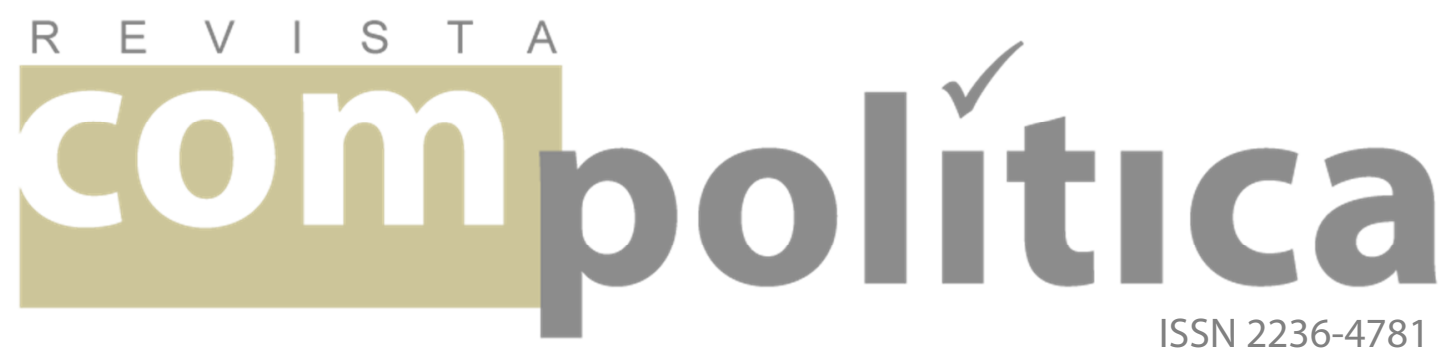

\title{
Mobilização política por e-mail: uma análise da Avaaz como ator-rede
}

\section{[Political mobilization by e-mail: an analysis of Avaaz as an actor-network]}

\section{RESUMO}

0 artigo procura analisar as práticas e os fluxos da operação de uma organização que usa a internet de forma intensa, a Avaaz, à luz da teoria do ator-rede na vertente elaborada por Bruno Latour. Para tal, começa por apresentar essa vertente teórica que procura inserir objetos materiais na análise sociológica de modo a caracterizar esta organização de campanhas como um conjunto heterogêneo composto por humanos e não humanos que se configuram a cada campanha lançada. 0 artigo se concentra na caracterização dos membros da Avaaz, sua distribuição ao redor do mundo, os alertas de e-mail que são enviados aos membros, as oportunidades de participação oferecidas, os diferentes temas abordados e os alvos construídos a cada campanha.

Palavras-chave: Mobilização; Ator-rede; Avaaz

\section{CASTAÑEDA, Marcelo}

Doutor em Ciências Sociais pelo CPDA/UFRRJ e pósdoutorando no PPGCOM-UERJ

$[\mathrm{PhD}$ in Social Sciences from the Social Sciences in Development, Agriculture and Society Graduate Program at Rural Federal University of Rio de Janeiro and post-doctoral candidate at Communication Graduate Program at Rio de Janeiro State University] <celocastaneda@gmail.com>

\section{ABSTRACT}

The article analyzes the Avaaz (an organization that uses the internet intensively), their practices and operating flows in light of the actor-network theory developed by Bruno Latour. To do this, the paper begins by presenting this theoretical model that seeks to insert material objects in sociological analysis in order to characterize the organization of campaigns as a heterogeneous group composed of human and non-human that are configured to each campaign launched. The article focuses on the characterization of Avaaz members, their distribution around the world, e-mail alerts that are sent to members, the participation opportunities offered, the different themes and targets built each campaign.

Keywords: Mobilization; Actor-network; Avaaz. 


\section{Mobilização política por e-mail: uma análise da Avaaz como ator-rede}

CASTAÑEDA, Marcelo

W este artigo me baseio em observações acerca da Avaaz, que recentemente como fruto de uma difusão global, progressiva e desigual da internet, mais especificamente, dos diferentes usos desta pelo campo político (CASTELLS, 2003). Esta organização se define como uma "comunidade de mobilização online que leva a voz da sociedade civil para a política global"1.

Desde o início de 2007, a Avaaz fabrica campanhas sobre um leque amplo de temáticas, compreendendo meio ambiente $\mathrm{e}$ biodiversidade; direitos humanos; democracia; ações contra a corrupção; as corporações; as guerras; a pobreza e a desigualdade. É sobretudo através dessas campanhas que a Avaaz consegue projetar sua atuação em diferentes escalas, configurando redes sociotécnicas que articulam ferramentas da internet, os ativistas que trabalham para a organização e um conjunto heterogêneo de membros, ou seja, de indivíduos de diferentes países mobilizados com a internet. Esta forma de organização, tendo a composição de campanhas como elemento central, permite à Avaaz exercitar múltiplas formas de conexão e associação entre esses diferentes elementos em seu dia a dia.

A cada campanha fabricada por esta organização e outras semelhantes, as tecnologias da internet - no caso em tela os alertas de e-mail e o site da Avaaz, bem como plataformas como Facebook e

${ }^{1}$ Disponível em: <http://www.avaaz.org/po/about.php>. Acesso em: 20/07/2011. 
Twiter - possibilitam o acréscimo contínuo de novas conexões e associações possíveis entre indivíduos, grupos e objetos materiais. Ao ser vista como um ator-rede (LATOUR, 2005), que age como um mediador sociotécnico, a Avaaz parece configurar um tipo de ação coletiva coordenada que é específica das sociedades contemporâneas, em especial por ser fortemente associada à internet.

A Avaaz pode ser vista como um ator-rede ao mobilizar sua rede de membros com suas campanhas multitemáticas, formando coletivos heterogêneos a cada oportunidade de participação ${ }^{2}$ voltada para o engajamento de membros, considerando que as tecnologias da internet atuam como mediadores das ações que são tomadas pela organização e seus profissionais, que passam a constituir um conjunto que pode ser apreendido como um mediador sociotécnico.

Diferentes atores, tais como os profissionais que articulam as campanhas e os membros, emergem a partir destas associações entre humanos e não humanos. A Avaaz distribui e organiza essas diferentes agências de um modo determinado, incidindo em certos fluxos, canalizando atenção para certos temas, propondo certo tipo de estratégia e de guerra em rede.

\section{A teoria do ator-rede}

Para Latour (2005), a teoria do ator-rede tenta tornar a sociologia sensível frente à dificuldade apresentada pelos coletivos em relação às montagens com muitos elementos, entre humanos e não

\footnotetext{
${ }^{2}$ Utilizo o termo "oportunidade de participação" como uma categoria descritiva que se refere às possibilidades que a Avaaz disponbiliza em suas campanhas, tais como petições eletrônicas, envio de mensagens, pedidos de doação, realização de telefonemas e criação de petições.
} 
humanos. 0 sentimento de crise nas sociedades contemporâneas pode ser explicado da seguinte forma: uma vez alargado o leque de entidades, as novas associações não formariam novas montagens vivas. Nesta brecha que se abre, a política pode ser redefinida como uma intuição, o que remete à insuficiência das associações como relações entre humanos, que são compostas para conceber um mundo comum. A sociologia não pode se contentar apenas com descrições das associações entre humanos, nem somente apreciar a multiplicidade de novas conexões, mas seguir e descrever estas conexões.

As tecnologias da internet podem ser vistas como objetos, elementos heterogêneos, não humanos, que podem se tornar atores visíveis que agem na unificação de coletividades em um mundo comum, como pode ser visto nas campanhas da Avaaz. Essa perspectiva remete a um entrelaçamento entre humanos e não humanos, permitindo falar de um processo de imbricamento socioténico. Neste contexto, uma organização como a Avaaz não pode ser analisada sem considerar os papéis exercidos pelas tecnologias da internet nas suas campanhas, tendo em vista que estas tecnologias estão na base dos próprios processos que constituem a Avaaz como uma organização.

A questão-chave para a análise sociológica na perspectiva da teoria do ator-rede passa por uma decisão entre deduzir causas e efeitos que estavam dados como potenciais a priori ou substituir muitas causas possíveis por uma série de atores-rede. Para a teoria do atorrede, nenhum laço ou grupo é socialmente durável: o mundo socialse faz por meio de interações locais, mantendo um aspecto provisório, instável e caótico. Latour (2005) abre um caminho para mobilizar elementos heterogêneos - objetos materiais, não humanos - sem abrir mão de invocar o poder da explicação sociológica. $\mathrm{O}$ autor assinala que a ação não se dá sob o 
controle total da consciência e, assim, pode ser sentida como um nó ou um conglomerado de conjuntos de agências surpreendentes que devem ser lentamente desembaraçadas. Se o objetivo é entender as relações e processos que possibilitam que vários indivíduos façam a mesma coisa ao mesmo tempo, a ação passa a ser vista como uma surpresa, uma mediação ou um evento.

As tecnologias da internet atuam em todos os processos deflagrados pela Avaaz, desde a fabricação das campanhas até o engajamento e participação dos membros. Na perspectiva da teoria do ator-rede, um ator não é uma fonte de ação, mas um alvo móvel num vasto conjunto de entidades que atravessam a ação. Para reter sua multiplicidade, Latour (2005) procura reativar as metáforas implicadas na palavra ator, ressaltando que nunca se tem clareza de quem e o que está agindo quando nós agimos, tal como um ator no palco nunca está sozinho em sua ação ${ }^{3}$.

O autor defende que as análises sobre a determinação da ação devem partir das incertezas e controvérsias sobre quem e o que está agindo quando "nós" agimos, incluindo aí o sociólogo ou pesquisador, sendo que não há como saber se as fontes de incerteza residem no analista ou no ator. Se um ator é um ator-rede, ele representa a maior fonte de incerteza sobre a origem da ação, que é "deslocada, emprestada, distribuída, sugerida, influenciada, dominada, traída, e traduzida" (LATOUR, 2005, p. 46). Considerando que o social ainda não está pronto e acabado, os sociólogos devem perseguir os traços de hesitações dos atores, que se manifestam ao agir.

\footnotetext{
${ }^{3}$ Latour (2005) recorre a Erwing Goffman, que mostrou que se encerram as certezas quando o jogo começa e surgem as seguintes questões: isso é verdade? É falso? A reação da audiência conta? E a iluminação? O que a equipe está fazendo nos bastidores? A mensagem do dramaturgo está sendo fielmente representada?
} 
A maioria das teorias da ação não entende os deslocamentos, pois geralmente "o segundo termo está previsto pelo primeiro: 'Dê-me a causa e eu lhe darei o efeito'" (LATOUR, 2005, p. 58). Desta maneira, causas e efeitos são tidos como intermediários, ou seja, nada estará presente nos efeitos que não esteja presente nas causas. O autor assinala um equívoco nesta explicação, pois sendo assim, basta se concentrar nas causas e descartar os efeitos. Isso não acontece se os dois termos forem vistos como mediadores, tendo em vista que as causas não permitem deduzir efeitos, como se estivessem simplesmente oferecendo situações, circunstâncias e precedentes. Neste caso, muitos elementos imprevisíveis podem aparecer entre as causas e os resultados: se os termos forem tratados como mediadores que desencadeiam outros mediadores, uma série de situações novas seguirá, tendo em vista que eles fazem coisas que fazem outras coisas além do esperado.

Latour (2005) mostra que a solução dos intermediários desenha mapas do mundo que são compostos por algumas agências, seguidas por trilhas de consequências que não passam de efeitos, expressões ou reflexos de alguma outra coisa. $\mathrm{Na}$ solução dos mediadores, os mapas trazem concatenações de mediadores, onde cada ponto está plenamente em ação. Assim, uma questão-chave é decidir se o pesquisador ou analista deve tentar deduzir algumas causas como se estivessem na origem de uma série de efeitos que estavam lá em potencial, ou se tenta substituir as causas se seus possíveis efeitos por uma série de atores-rede. Para a teoria do ator-rede, a questão não é decidir quem está agindo e como, mas passar de uma certeza para uma incerteza em relação à ação, decidindo o que está agindo e como. O autor considera que se a ação é deslocada, ela não pertence a nenhum lugar ou ator específico, torna-se distribuída, variada, 
múltipla e continua a representar algo como um quebra-cabeça, para os analistas e para os atores.

\section{Avaaz como ator-rede}

Os membros da Avaaz, que são construídos por esta organização, ou seja, eles não existem a priori, compõem parte fundamental da rede mobilizada pela organização, conformando o público para o qual este ator-rede político se volta com a fabricação das campanhas. A Avaaz considera como membro qualquer indivíduo que em algum momento tenha cadastrado seu e-mail na sua base de dados ao participar de algumas das campanhas deflagradas. Pela lente da teoria do ator-rede, os membros da Avaaz - que já somam mais de 41 milhões de indivíduos em todo o mundo - compõem parte da rede mobilizada pela organização através de suas campanhas, que são mediadas pelas tecnologias da internet, em especial os alertas de $e$ mail e o site da Avaaz. Neste artigo, utilizo a categoria nativa "membro" para tratar os destinatários de mensagem que são mobilizados pelos e-mails desta organização.

A Avaaz afirma ter membros em todos os 194 países do mundo. Em números absolutos, o Brasil é o país que possui a maior quantidade de membros cadastrados na base de dados da Avaaz, seguido pela França, Alemanha, Itália, EUA, Espanha, Reino Unido e Canadá, sendo que estes oito países possuem mais de um milhão de membros cada.

Torna-se importante ressaltar que o potencial de mobilização que a Avaaz apresenta por meio do envio dos seus alertas de e-mail não é uniforme ao redor do mundo. Além disso, a Avaaz atinge pouco mais que $4 \%$ da população da França (4,55\%), por exemplo, país que apresenta a melhor relação entre membros e habitantes, e 3,03\% da 
população brasileira, país com o maior número absoluto de membros, o que mostra uma penetração reduzida em cada região. Isso pode assumir uma complexidade maior se considerarmos que cada país possui variações na população que tem acesso à internet, o que não foi feito aqui. De forma geral, as campanhas da Avaaz parecem mobilizar mais na Europa, na América Latina e nos EUA do que em países localizados nos continentes africanos e asiáticos, como a China.

A principal forma de mobilização da Avaaz é o envio de alertas pela organização, ou seja, e-mails com textos que contextualizam as campanhas em pauta e são enviados frequentemente para a caixa de entrada de mensagens dos seus membros. Esses e-mails podem ser enviados para todos os membros da organização ao redor do mundo, no caso de campanhas globais, ou para parte destes membros, no caso de campanhas nacionais ou regionais. Essas mensagens costumam conter alguns links que, uma vez clicados, conduzem para uma área do site da Avaaz, que permite o engajamento dos membros em algum tipo de ação prevista pelas campanhas propostas pela organização.

Como uma regra geral, a Avaaz procura enviar pelo menos um - mas não mais do que dois - alertas de e-mail por semana para comunicar suas ações aos seus membros em 16 línguas diferentes ${ }^{4}$, evitando saturá-los. Somente em campanhas com espectro global todas as mensagens são enviadas para todos os e-mails cadastrados nestas línguas ao mesmo tempo. Isso quer dizer que nem todas as campanhas são traduzidas e enviadas para todas as línguas.

\footnotetext{
${ }^{4}$ Eis as possibilidades: português, inglês, árabe, alemão, russo, francês, espanhol, coreano, chinês, chinês "tibetano", japonês, holandês, italiano, hebreu, turco e polonês. Alguns destes códigos linguísticos foram identificados utilizando a ferramenta Google Tradutor.
} 
Ao atuar como um mediador sociotécnico, sobretudo por meio das campanhas, a Avaaz se constitui como um ator-rede que compõe novas configurações da ação coletiva. Estas campanhas abrem possibilidades de agenciamentos e engajamentos em processos de formação de coletivos políticos heterogêneos viabilizados pela internet. Estes grupos são compostos por múltiplas associações e conexões possíveis pelas inter-relações entre tecnologias da internet e ações e práticas de atores sociais, tais como os profissionais que atuam nesta organização, que se comunicam mediante o uso de plataformas de comunicação como Skype e Gtalk, e aqueles indivíduos espalhados pelo mundo e cadastrados na base de dados da Avaaz, que são denominados como membros, que agem no site da Avaaz a partir do momento em que clica nos links no corpo das mensagens enviadas pela organização ou mesmo em algum site de rede social. Para dar conta da complexidade inerente aos processos da Avaaz, elaborei um esquema que apresento na Figura 1 abaixo. 
Figura 1 - Avaaz como ator-rede

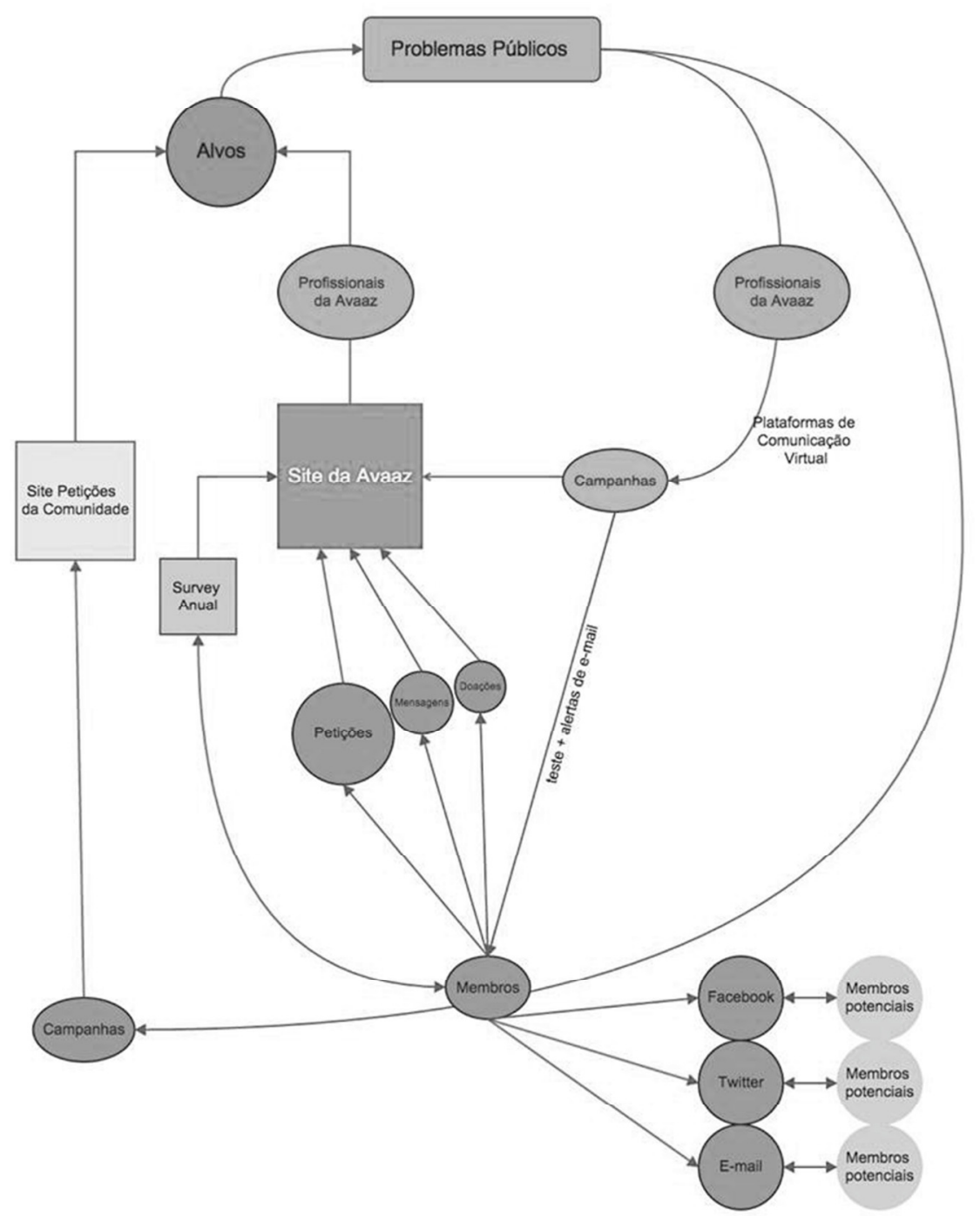

Com base neste esquema, os imbricamentos sociotécnicos em jogo nas campanhas deste ator-rede podem ser observados sob pelo menos quatro diferentes perspectivas:

(1) no processo de definição das campanhas e de construção da agenda a ser trabalhada em cada campanha, quando as tecnologias da internet mediam as práticas comunicativas entre os profissionais da Avaaz em seus diferentes contextos, bem como na interação com os alvos de cada campanha. Com o site Petições da Comunidade, esse processo pode acontecer em uma esfera mais individualizada, na 
medida em que qualquer indivíduo pode criar uma campanha. Também, como parte da construção da agenda, a realização de um survey anual entre os membros aparece como um imbricamento sociotécnico importante nos processos da Avaaz.

(2) na formação contínua dos grupos: as diferentes listagens de membros são formadas a cada campanha e se alteram no curso de ação, ou seja, mudam a cada instante de uma campanha em curso, a cada novo engajamento ou saída de um membro viabilizado pelas tecnologias da internet em uma oportunidade de participação proposta pela organização. Estes grupos podem ser entendidos como coletivos políticos heterogêneos, abertos e incompletos, cuja conformação é resultado das múltiplas associações e conexões que se tornam possíveis pelas inter-relações que se estabelecem entre as tecnologias da internet e práticas de atores sociais, incluindo aqui os profissionais da Avaaz, os chamados membros da organização e suas respectivas redes de contatos.

(3) nas ações dos membros da organização, direcionados pela Avaaz através de um campo bastante restrito de oportunidades de participação em cada campanha: assinar petições, realizar doações financeiras, enviar mensagens e realizar telefonemas para alvos préestabelecidos. Outra forma de ação mediada pelas tecnologias da internet emerge quando estes participantes provocam o engajamento de novos membros, mediante o compartilhamento de links de campanhas em seus perfis em redes sociais como Facebook e Twitter, ou para suas diferentes redes de contato por e-mail. O site "Petições da Comunidade" e o survey anual também configuram parte das ações dos membros.

(4) nas diferentes tecnologias da internet que participam tanto deste processo de formação contínua dos coletivos, entre as quais os $e$ - 
mails, o site da Avaaz e os sites de redes sociais como Facebook e Twitter; quanto da estruturação de repertórios de ação definidos pelos ativistas da organização a cada momento e em cada campanha, tais como Skype, Gtalk, entre outras.

Em vez de considerar o tipo de figuração do ator coletivo, com a teoria do ator-rede, Latour (2005) sugere se voltar para a gama de mediadores que um ator como a Avaaz é capaz de implantar na formação contínua dos grupos, nas ações tomadas neste processo e nos objetos que participam das campanhas. $O$ autor afirma que a continuidade de qualquer curso de ação raramente consiste de conexões entre seres humanos, para as quais as habilidades humanas básicas poderiam ser suficientes, ou de conexões entre objetos, mas muito provavelmente de um entrelaçado complexo de humanos e objetos, constituindo o que estou chamando aqui de um imbricamento sociotécnico.

Na Figura 1 acima, as diferentes setas representam as tecnologias da internet, que podem ser vistas como objetos materiais que agem como mediadores, abrindo possibilidades para conexões e associações no processo incompleto e aberto de formação de coletivos políticos heterogêneos e nas agências que compõem as campanhas da Avaaz. É através destas tecnologias que tentarei entender o processo de imbricamento sociotécnico que está em jogo nas campanhas da Avaaz.

As tecnologias da internet atuam como mediadores com os humanos nas ações da Avaaz. Na fabricação das campanhas, participam ativamente das ações que se desenvolvem, em conjunto com os profissionais da Avaaz. Mais que isso, são estas tecnologias que viabilizam as ações de planejamento e organização entre 
profissionais que estão espalhados pelo mundo. Sem elas não haveria fabricação das campanhas.

Considerando as incertezas da ação, em cada campanha da Avaaz, mais ainda, em cada oportunidade de participação, não há qualquer previsão de quem irá se engajar nas propostas da organização mediadas pelas tecnologias da internet, ainda que existam testes efetuados antes das campanhas serem lançadas. Ao abrir o e-mail, o membro deve clicar em um link e inserir dados em uma área específica do site para se engajar. Essas ações só se tornam possíveis porque as tecnologias da internet atuam como mediadoras da ação possibilitada pela Avaaz, que pode ser vista como um ator-rede. Da mesma forma, não há qualquer controle sobre os possíveis compartilhamentos de links em sites de redes sociais, também mediados pelas tecnologias da internet. As incertezas estão presentes em cada ação, ou seja, distribuídas neste fluxo de associações que constituem a Avaaz como um ator-rede.

Latour (2005) utiliza o termo "coletivo" para designar o projeto de montagem de novas entidades que ainda não se reuniram e, por isso, aparecem claramente como não sendo compostas de elementos materiais e sociais. A teoria do ator-rede afirma que a continuidade de qualquer curso de ação raramente depende de conexões entre seres humanos, para os quais as habilidades humanas básicas poderiam ser suficientes, ou de conexões entre objetos, mas muito provavelmente de um entrelaçado complexo envolvendo humanos e objetos.

Pela sua forma de operar com as tecnologias da internet, a Avaaz atua como um ator-rede na medida em que forma coletivos heterogêneos que entrelaçam humanos e não humanos, constituindo uma cadeia de associações que atravessa todos os processos inerentes a esta 
organização. Fazer parte deste ator-rede remete a uma forma multissituada de se posicionar sobre uma multiplicidade de questões e temas, gerando amplificações, ordenamentos, condicionamentos e reduções de complexidade. A internet não remete apenas a uma mudança no meio através do qual circulam as informações, mas possibilita a conformação de novos coletivos e repertórios de ação, comprimindo o tempo-espaço e, muitas vezes, colocando em contato indivíduos que nunca se viram.

As campanhas, que se materializam nos textos das mensagens dos alertas de e-mail e suas extensões no site da Avaaz, são fabricadas por profissionais que atuam em diferentes partes do mundo detectando oportunidades para deflagrá-las, tendo como público os mais de 41 milhões de membros da Avaaz. Como membro da Avaaz e participante da rede deste ator-rede, recebi 197 e-mails desta organização entre 04/01/2011 e 24/12/2013, período em que efetuei a pesquisa que serviu de base para este artigo.

A análise empreendida a seguir neste artigo volta-se para os elementos textuais destes alertas de e-mail que recebi como membro da Avaaz, tendo em vista que constituem a principal forma de mobilização e convencimento dos membros, bem como de comunicação das campanhas propostas pela organização. A importância dos e-mails foi destacada em entrevista realizada com um dos Campaign Directors da Avaaz.

O grande laço de comunicação é o e-mail. Se a pessoa foi pro site é porque ela já se inteirou do assunto de alguma maneira, seja pelo e-mail, seja porque alguém colocou no Facebook, fez um comentário, tem uma referência, quando ela tem uma propensão de assinar muito grande. Mas o processo de convencimento não é no site, esse processo de convencimento é no e-mail (entrevista com Pedro Abramovay, realizada em 05/09/2012). 
Analisando os alertas de e-mail - que recebi na qualidade de membro - como material empírico a ser trabalhado na seção seguinte, pude perceber que as campanhas da Avaaz apresentam algumas variações nas oportunidades de participação oferecidas. As petições são o principal formato utilizado, mas os repertórios de ação estruturados pela Avaaz envolvem também: pedidos de doações, envio de mensagens, realização de telefonemas para alvos determinados, entre outros.

\section{Alertas, temas e alvos das campanhas}

Cabe destacar o número de alertas que recebi por mês, no período de janeiro de 2011 até dezembro de 2013, totalizando 197 e-mails. Podese perceber que a regra de enviar pelo menos um alerta e no máximo dois por semana vem sendo cumprida, ainda que a organização tenha enviado somente três alertas em setembro de 2012 e dois alertas em fevereiro de 2013. No geral, a média apurada foi de 5,61 alertas por mês, o que remete a pouco mais do que um por semana.

A quantificação das diferentes modalidades de ação propostas pela Avaaz nos e-mails que me foram enviados durante o período analisado mostram que as petições compreendem a grande maioria das oportunidades de participação comunicadas pela Avaaz no período investigado, tendo em vista que foram 120 alertas comunicando petições, compreendendo 59,4\% dos e-mails enviados no período. Estou considerando a oportunidade de participação enviada como link no corpo do e-mail, pois ao final de cada alerta existe uma possibilidade de efetuar uma doação.

Outras oportunidades de participação associadas a campanhas da Avaaz incluíram os pedidos de doação (20 alertas - 9,9\%) e o envio de 
mensagens para alvos pré-estabelecidos (18 alertas - 8,9\%). Os alertas de e-mail também foram usados para convocar os membros para efetuar ligações telefônicas (14 alertas - 6,9\%), bem como para fazer comunicados sobre as ações da Avaaz (12 alertas - 5,9\%).

Na rubrica "outras" agrupei os e-mails que estimulavam os membros a criarem suas próprias petições no site "Petições da Comunidade", bem como chamadas para participação na pesquisa anual da organização. Também se refere a ações específicas, tais como enviar uma foto e mensagens de apoio a uma campanha, comentários com sugestões e ideias para tirar Renan Calheiros da presidência do Senado, entre outras. Além disso, também inseri nesta rubrica mensagens de diferente teor, que não propunham uma ação específica: a possibilidade de fazer um comentário sobre uma campanha vitoriosa, outra com agradecimentos por uma doação que fiz neste período, um pedido de resposta a e-mail por conta de mudanças na política do Gmail, e a proposta de contar história pessoal no site da Avaaz.

Considerando o período pesquisado, os alertas de e-mail divulgaram um total de 105 campanhas, que podem ser enquadradas em sete grandes temáticas. A Tabela 1 mostra a frequência com que essas temáticas foram desenvolvidas pela Avaaz. As temáticas do meio ambiente e biodiversidade juntamente com a dos direitos humanos foram as mais frequentes entre as campanhas deflagradas no período. 
Tabela 1 - Temas das campanhas

\begin{tabular}{l|lc}
\hline Temática & Número de campanhas & $\%$ \\
\hline Pelo meio ambiente e pela biodiversidade & 30 & 28,6 \\
Pelos direitos humanos & 30 & 28,6 \\
Pela democracia & 20 & 19 \\
Contra as corporações e ações de grupos privados & 8 & 7,6 \\
Contra a corrupção & 7 & 6,7 \\
Contra a guerra & 6 & 5,7 \\
Contra a pobreza e a desigualdade & 4 & 3,8 \\
TOTAL & 105 & 100,0 \\
\hline
\end{tabular}

Fonte: Avaaz, a partir dos alertas de e-mail recebidos entre 2011 e 2013

Ao longo da pesquisa, pude perceber que existem campanhas da Avaaz em prol de causas e outras que procuram incidir sobre questões ou problemas específicos. No que diz respeito às campanhas em prol de "meio ambiente e biodiversidade", destacam-se temáticas relativas à preservação ambiental e manutenção de espécies animais, tais como abelhas, rinocerontes e tigres, entre outras. Nesta rubrica também inseri questões como eficiência energética e em defesa da energia renovável. Na rubrica "pelos direitos humanos", agrupei temáticas de campanhas relacionadas com questões contrárias à violência contra crianças e mulheres, contra o machismo, a homofobia e situações de abuso e tortura, chamadas por justiça, igualdade e paz, e em defesa das comunidades tradicionais. Quando me refiro às campanhas "pela democracia", compreendo campanhas pela democracia e pela liberdade de expressão ao redor do mundo, em especial contra Estados, mas também contra empresas. 
$\mathrm{Na}$ rubrica "contra as corporações e ações de grupos privados", incluo questões envolvendo corrupção privada no poder público, contra os "lucros obscenos de empresas", a favor da regulação dos mercados, pela segurança no trabalho e pela regulação das empresas. A rubrica "contra a corrupção" buscou organizar um conjunto de temas associados à defesa da democracia, contra privilégios de políticos e pela dignidade. Em "contra a guerra", a violência figura como alvo principal das campanhas, mas questões tais como soberania e direitos humanos também se fazem presentes. $\mathrm{Na}$ rubrica "contra a pobreza e a desigualdade" estão presentes questões como erradicação da pobreza global, corte nos "lucros obscenos de empresas", luta contra a desigualdade e educação para todos.

Os alertas de e-mail que divulgam as campanhas da Avaaz parecem mobilizar um público específico e difuso. Como não foi possível obter dados sobre o perfil deste público junto à organização, dentro desses limites, uma questão que interessa é refletir sobre como se dá o engajamento destes membros nas campanhas da Avaaz, procurando também entender as dinâmicas de participação e mobilização que levam a este tipo de engajamento.

Geralmente, em frente aos seus computadores, notebooks, tablets ou telefones celulares, em casa ou onde quer que exista uma conexão à internet, estes indivíduos recebem um e-mail, contendo informações sobre uma campanha em curso. Naquele momento, os membros podem clicar em um link que aparece no corpo da mensagem recebida. Esse clique os leva até uma página armazenada no site da Avaaz, onde se apresenta a possibilidade de assinar uma petição, enviar uma mensagem ou efetuar uma doação. Existem campanhas que podem propor que estes indivíduos realizem telefonemas para alvos pré-estabelecidos ou compartilhem dizeres nos murais do Facebook de algum destes alvos. Estes alertas também podem conter 
somente comunicados acerca da atuação da Avaaz ao redor do mundo, geralmente assinados pelo canadense Ricken Patel, portavoz oficial da organização.

Trata-se de um tipo de ativismo que envolve um baixo custo de participação, tanto para os indivíduos que se engajam nessas ações como para a organização, tendo em vista que em alguns minutos as ações em pauta podem ser executadas pelos membros da Avaaz sem exigir qualquer tipo de encontro presencial. Isso, no entanto, não faz com que esta forma de mobilização, participação e engajamento deixe de ter suas particularidades.

Boa parte do engajamento de novos membros se dá na medida em que parte considerável dos indivíduos que recebem os e-mails da Avaaz compartilha suas ações através de links nos seus murais do Facebook, principalmente (de 4,8\% a 41,06\% dos membros, a depender da campanha, em média em torno de $25 \%{ }^{5}$ ), mas também na timeline do Twitter (algo entre 0,4\% e 7,31\% dos membros, em média 4\%), ou mesmo enviando os alertas de e-mail que recebem para suas redes de contato de e-mail, o que ocorre com menos frequência. $\mathrm{O}$ uso de sites de redes sociais como Facebook e Twitter, bem com o envio de e-mails para redes de contato pessoal, parecem dar corpo a um processo de autocomunicação de massas (CASTELLS, 2009), pelo qual vários emissores-receptores se comunicam com outros emissoresreceptores com a internet, indo além da coordenação da Avaaz.

A autocomunicação de massas tem potencial para atingir uma audiência global através de redes P2P (peer-to-peer) e conexões de internet. Trata-se de uma comunicação multidimensional, na medida em que a digitalização do conteúdo e os softwares sociais, geralmente baseados em programas abertos que podem ser livremente baixados,

${ }^{5}$ Percentuais aferidos entre as 105 campanhas identificadas entre 2011 e 2013. 
permitem a reformatação de quase todos os conteúdos em quase todos os formatos, sendo crescentemente distribuídos pelas redes wireless. Também é autogerada no conteúdo, autodirigida na emissão e autosselecionada na recepção por muitos que se comunicam com muitos.

Castells (2009) entende que a autocomunicação de massas configura um novo domínio da comunicação, e ultimamente um novo meio, cujo eixo principal se baseia em redes de computador com linguagem digital e remetentes globalmente distribuídos, que interagem em escala planetária. Este meio não determina o conteúdo e o efeito das mensagens, mas apresenta potencial para uma diversidade ilimitada e produção autônoma da maior parte dos fluxos de comunicação que constroem significado na mente do público ${ }^{6}$.

O site da Avaaz pode ser visto como um centro de cálculo, na medida em que todas as campanhas ficam armazenadas nele, bem como os membros desta organização tem que acessar o site para assinar petições, enviar mensagens ou efetuar doações. Latour (2000) entende um centro de cálculo como um espaço em que se realiza uma translação capaz de mobilizar tudo o que pode ser inscrito e levado de um ponto periférico para outro mais central, e vice-versa. Esta translação remete a um trabalho complementar, que, no caso da Avaaz, complementa o trabalho dos alertas de e-mail que são

\footnotetext{
${ }^{6}$ Castells (2009) destaca que a revolução nas tecnologias da comunicação e as novas culturas de comunicação autônoma são processadas e moldadas, ainda que não determinadas, por organizações e instituições que são influenciadas por estratégias de negócio de busca pelo lucro e crescimento de mercado. A crescente interação entre redes de comunicação horizontais e verticais não significa que a mídia tradicional está sucumbindo diante destas novas e autônomas formas de geração e distribuição de conteúdo. 0 autor aponta um processo de complementaridade que proporciona uma nova realidade de mídia, cujos contornos e efeitos vão ser decididos pelos conflitos políticos e de negócios entre as posições dos donos das redes de comunicação pelo controle do acesso e tráfego em favor de seus parceiros de negócio e clientes preferenciais.
} 
enviados. Assim, a tarefa do site consiste em fazer com que muitos ajam como um só, seja simplificando as inscrições (no caso, as campanhas divulgadas pelos alertas de e-mail), seja mobilizando elementos, mas mantendo-os a distância (no caso de quem acessa estas inscrições de qualquer lugar do mundo pela internet).

O site funciona, portanto, como o local em que estão inscritas as diferentes campanhas deflagradas pela Avaaz, servindo de local de passagem obrigatória para os membros que se engajam nas oportunidades de participação propostas pela organização em sua mobilização. O site se constitui como um espaço que recebe, processa e direciona as diferentes ações dos membros, bem como dos articuladores de campanha, dos ativistas e especialistas consultados a cada campanha e dos alvos, complementando a função mediadora e mobilizadora dos alertas de e-mail. Assim, no site estão armazenados todos os links de campanhas, possibilitando seu rastreamento.

Por fim, cabe destacar os alvos destas campanhas, ou seja, para quem a Avaaz está dirigindo a mobilização dos seus membros. Na Tabela 2 abaixo, apresento um levantamento compreendendo os e-mails que recebi no idioma em português, a maioria dos alvos da Avaaz estão na escala nacional $(64,3 \%)$, com forte ênfase no Poder Executivo $(43,1 \%)$. Os organismos transnacionais e líderes mundiais aparecem com um percentual bem abaixo $(13,9 \%)$. 
Tabela 2 - Alvos da Avaaz

\begin{tabular}{l|lc}
\hline Alvo & Menções & $\%$ \\
\hline $\begin{array}{l}\text { Presidentes, Primeiros-Ministros, Governos, Ministros e } \\
\text { Chefes de Estado }\end{array}$ & 71 & 43,1 \\
Parlamentares (nacional) & 35 & 21,2 \\
Organismos Transnacionais & 18 & 10,9 \\
Empresas & 9 & 5,5 \\
Poder Judiciário & 7 & 4,2 \\
Líderes Mundiais & 5 & 3 \\
Outros & 20 & 12,1 \\
TOTAL & 165 & 100, \\
\end{tabular}

Fonte: Avaaz, a partir dos alertas de e-mail recebidos entre 2011 e 2013

\section{Considerações finais}

Esse panorama nos faz pensar que a Avaaz procura conferir visibilidade internacional para questões nacionais dentro do amplo leque de temas no qual atua, bem como que sejam aprovadas nos testes realizados junto a uma amostra dos membros. Dar visibilidade a questões nacionais, pressionando governos, pode ser visto como um dos principais objetivos das campanhas da Avaaz. Ainda que uma determinada causa em questão tenha um caráter que pode ser visto como nacional, a Avaaz procura construir visibilidade internacional, a fim de pressionar seus representantes em diferentes esferas Executivo, Legislativo e Judiciário - criando situações de mudança.

Fazendo referência às redes de defesa de direitos, Keck \& Sikkink (1998) assinalam que estas são significativamente transnacionais e nacionais: ao construir novas associações entre atores das sociedades civis nacionais, dos Estados e das organizações internacionais, estas 
redes multiplicam os canais de acesso ao sistema internacional. Em temas como meio ambiente e direitos humanos, que estão entre as principais temáticas tratadas pela Avaaz, por exemplo, estas redes tornam recursos internacionais acessíveis para novos atores em conflitos políticos e sociais na esfera nacional.

Com os aportes de Tarrow (2005), pode-se afirmar que este movimento de pressão da Avaaz sobre governos e Estados pode ser associado a um processo de internalização dos protestos, ou seja, a pressão desta organização que pretende atuar globalmente, mas fabrica campanhas que pressionam governos, confere visibilidade internacional a algumas causas que podem ser vistas como nacionais. 0 autor chama atenção para uma resistência à globalização, o que faz com que muitos dos ativistas cosmopolitas - grupo no qual os profissionais da Avaaz parecem se enquadrar - continuam a protestar no terreno doméstico, enquadrando suas demandas em termos concretos contra antagonistas visíveis, tais como os governos.

Neste sentido, vale ressaltar quatro tendências que Tarrow (2005) destaca quando trata deste processo de internalização: os cidadãos estão respondendo politicamente à intrusão de pressões e instituições externas nas suas vidas, sendo que protestos internalizados contra pressões externas configuram uma tendência, e, no caso desta pesquisa, a Avaaz parece ser mediadora dessas insatisfações na medida em que uma parte de suas campanhas tem como alvo os organismos multilaterais; as respostas domésticas a pressões externas encontram nas instituições o seu ponto crítico, sendo que os governos são os mais cobrados; capturados entre a pressão externa e as contingências internas, os governos se tornam alvos altamente vulneráveis e visíveis; e o internacionalismo, que insere pressões internacionais e enquadramentos globais na política 


\section{CASTAÑEDA}

doméstica, também provê canais para que os protestos locais sejam

difundidos horizontalmente além das fronteiras nacionais, bem como se movam verticalmente em escalas mais elevadas, como parece ser o caso com algumas das campanhas da Avaaz. 


\section{Referências}

CASTELLS, Manuel. A galáxia da Internet: reflexões sobre a Internet, os negócios e a sociedade. Rio de Janeiro: Jorge Zahar Ed., 2003.

Communication power. New York: Oxford University Press, 2009.

KECK, Margaret E.;SIKKINK, Kathryn. Activists Networks in International Politics. Ithaca and London: Cornell University Press, 1998.

LATOUR, Bruno. Ciência em ação: como seguir cientistas e engenheiros sociedade afora. São Paulo: Editora UNESP, 2000.

. Reassembling the Social - An Introduction to Actor-Network-Theory. New York: Oxford University Press, 2005.

TARROW, Sidney. The new transnational activism. New York: Cambridge University Press, 2005.

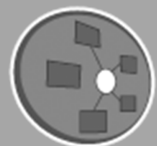

COMPOIITICA ASSOCIAÇĀO BRASILEIRA DE PESQUISADORES EM COMUNICAÇĀO E POLÍTICA

Diretoria da Associação/Director Board

Presidente | President

Fernando Lattman-Weltman (UERJ)

Vice-Presidente | Vice-President

Arthur Ituassu (PUC-Rio)

Secretária Executiva | Executive Secretary

Kelly Prudêncio (UFPR)

Corpo Editorial / Editorial Board

Editoras-Chefes: | Chief-Editors

Alessandra Aldé (UERJ) \& Maria Helena Weber (UFRGS)

Editores Executivos | Executive Editors

Fernanda Sanglard (UERJ), Rafael Cardoso Sampaio

(UFMG) \& Viktor Chagas (UFF)

Revisoras | Proofreaders

Fernanda Sanglard (UERJ) \& Isabele Mitozo (UFPR)
A Revista Compolítica é uma revista eletrônica da Associação Brasileira de Pesquisadores em Comunicação e Política

[Revista Compolitica is an electronic journal published by the Brazilian Association of Political Communication Scholars]

Ao citar este artigo, utilize a seguinte referência bibliográfica

[To cite this article, please use the following reference]

CASTAÑEDA, Marcelo. Mobilização política por e-mail: uma análise da Avaaz como ator-rede. In: Revista Compolítica 5 (1), 2015. 
